\title{
ARS GRÁFICA
}

Tipos de Sujeito 


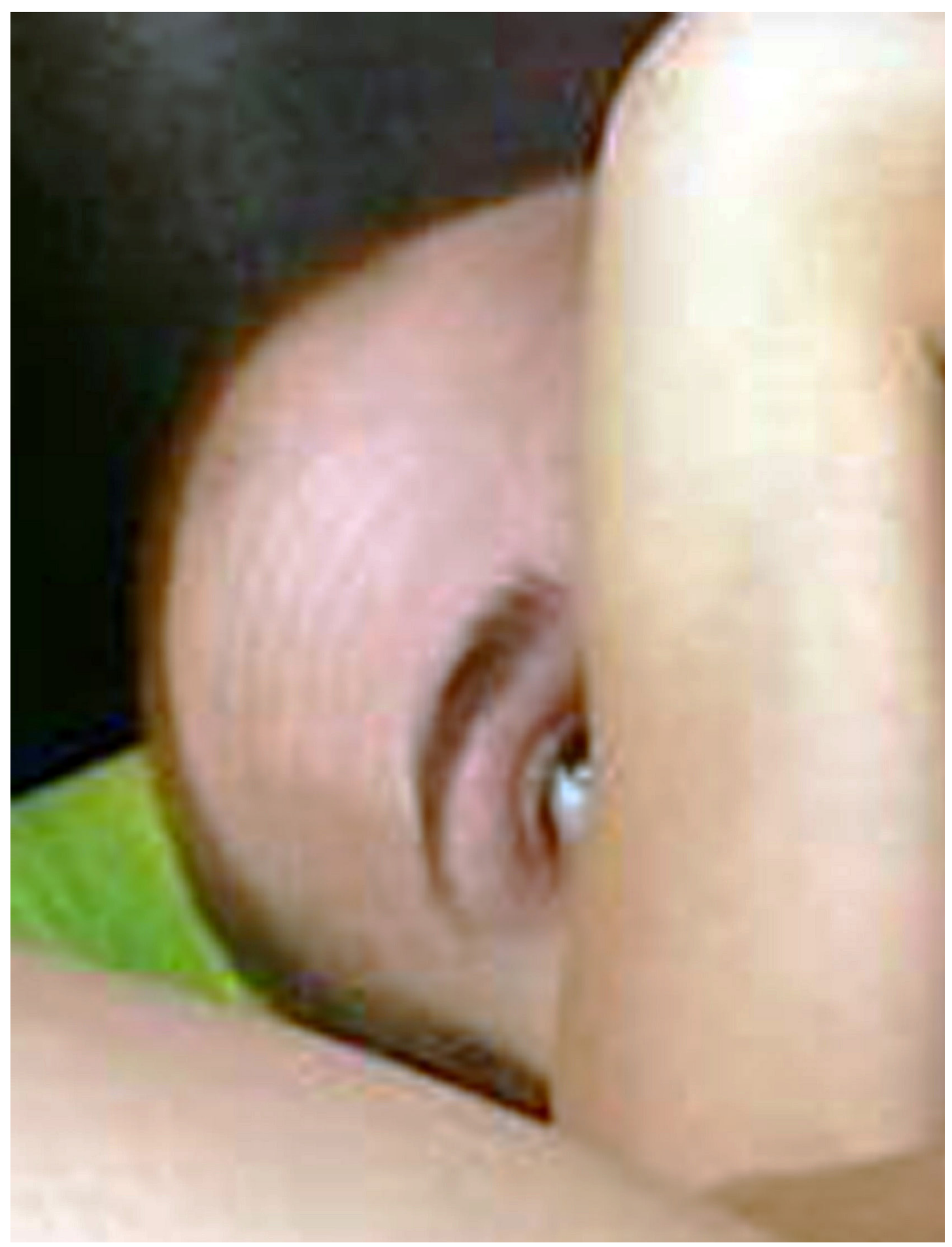




$$
F
$$




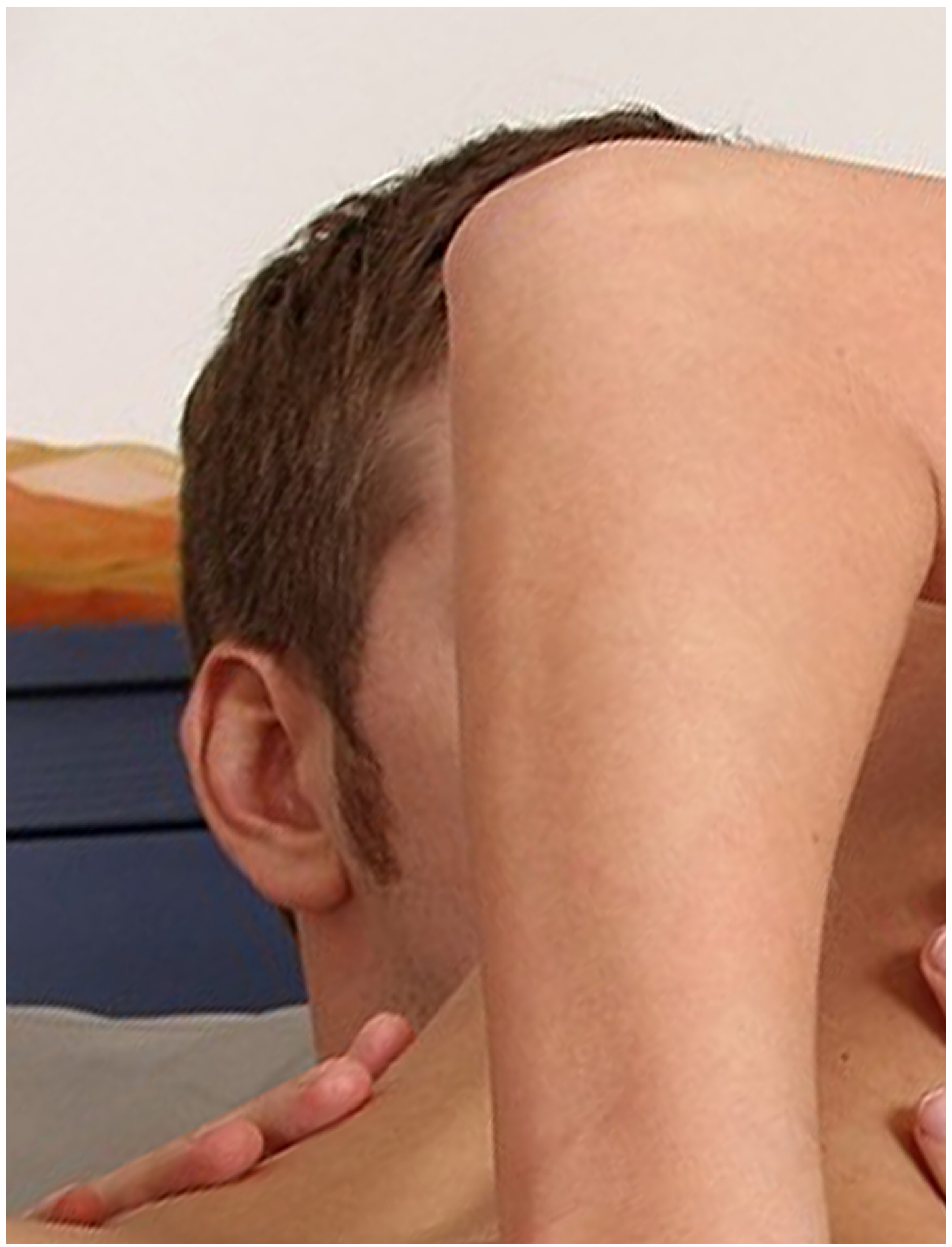




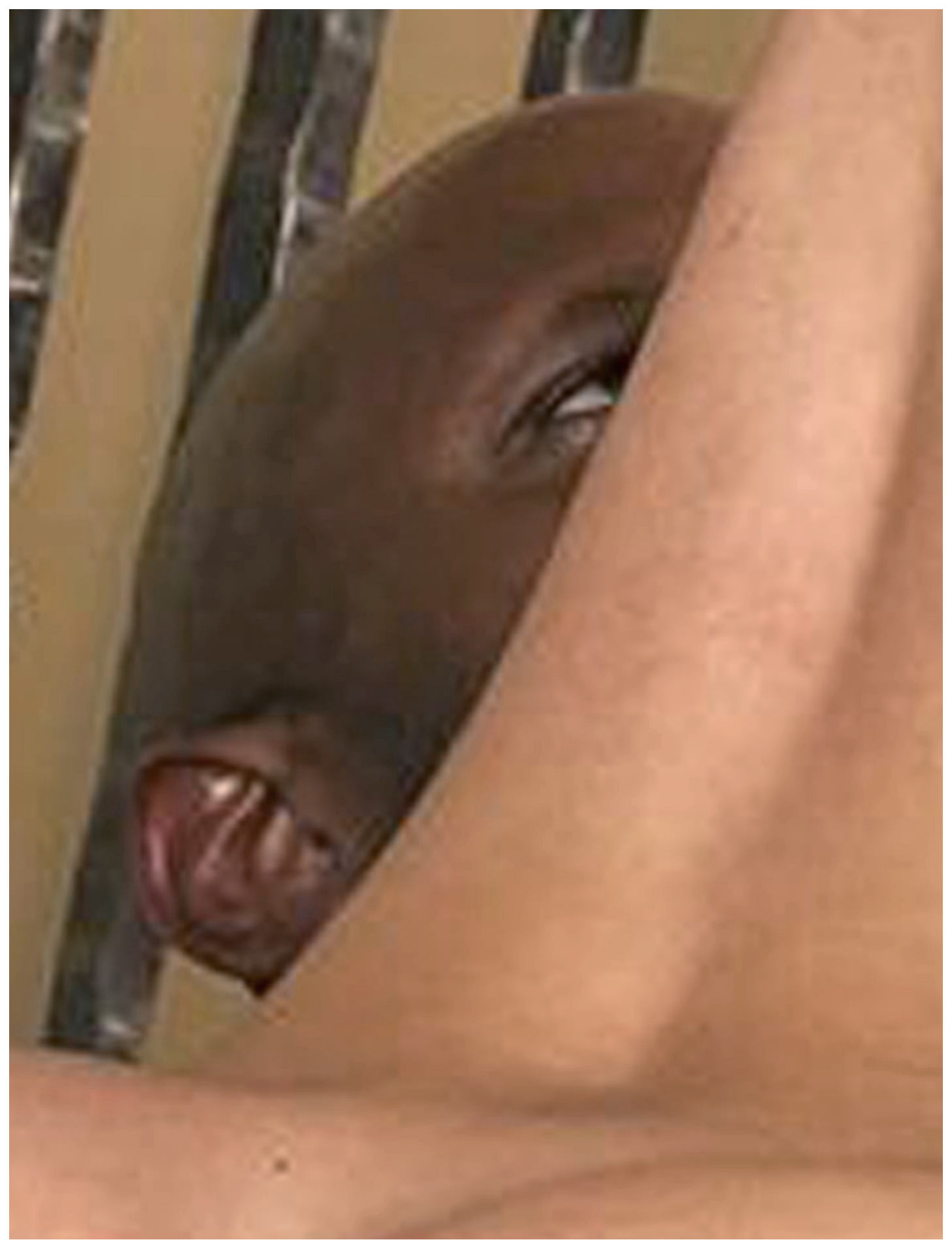




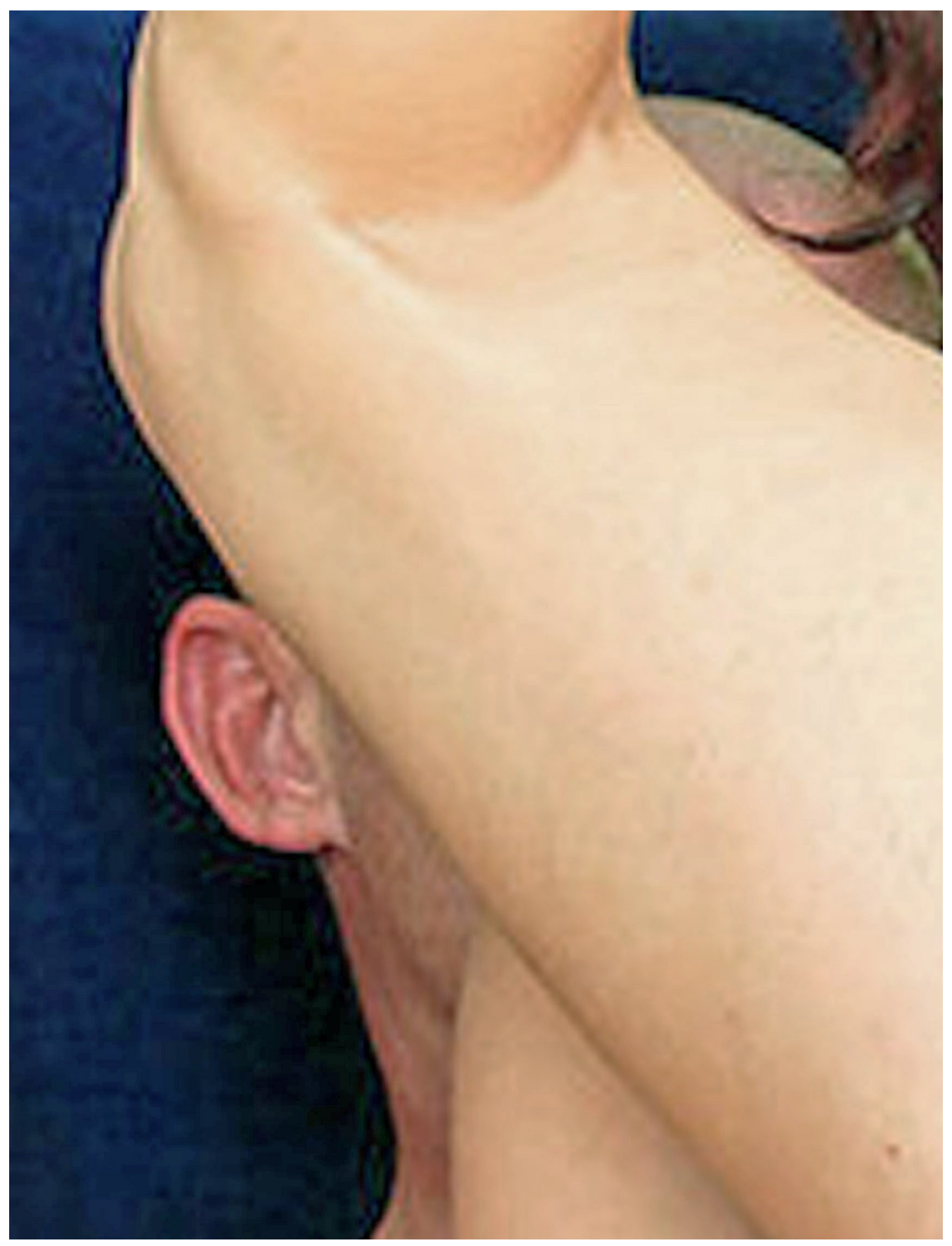




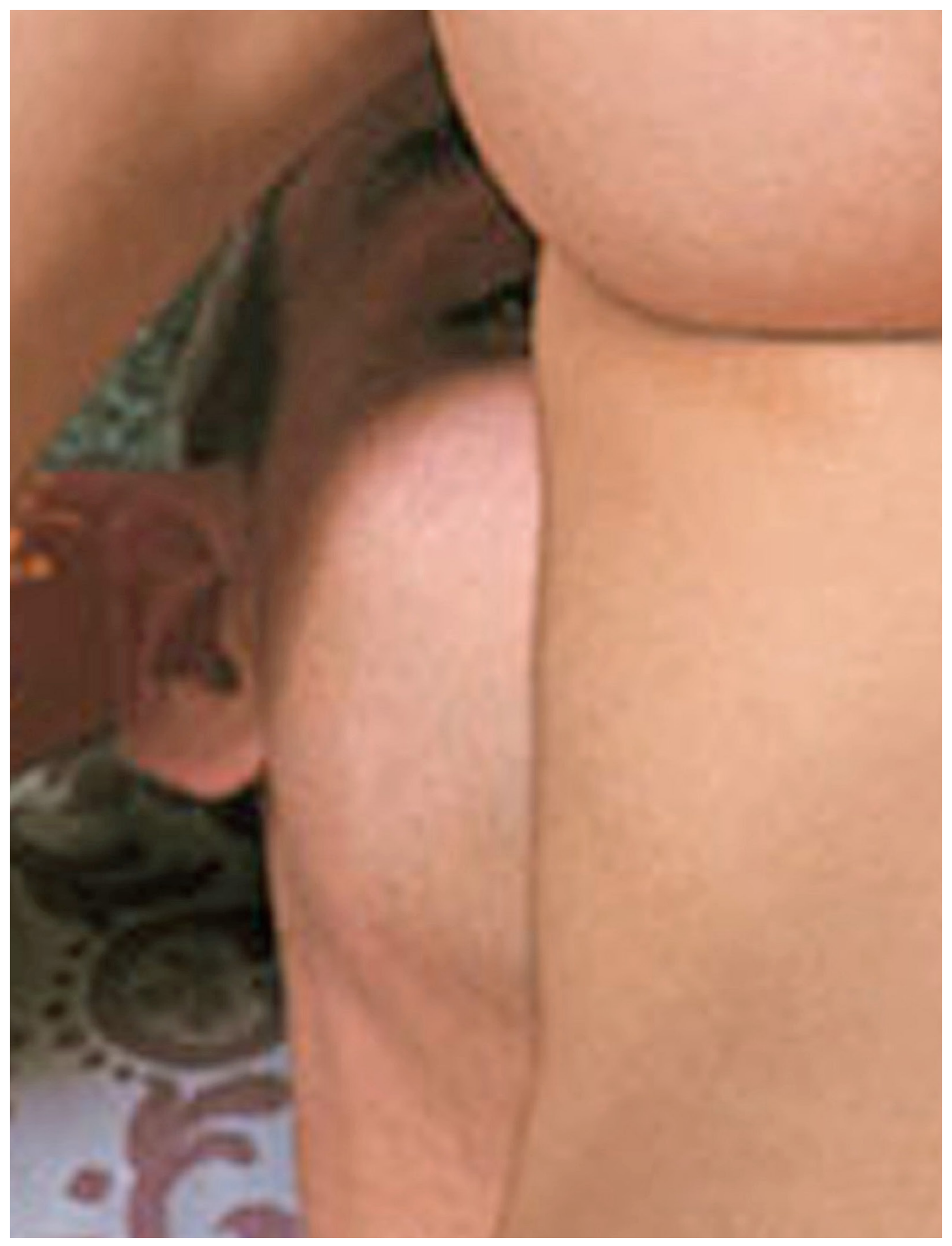




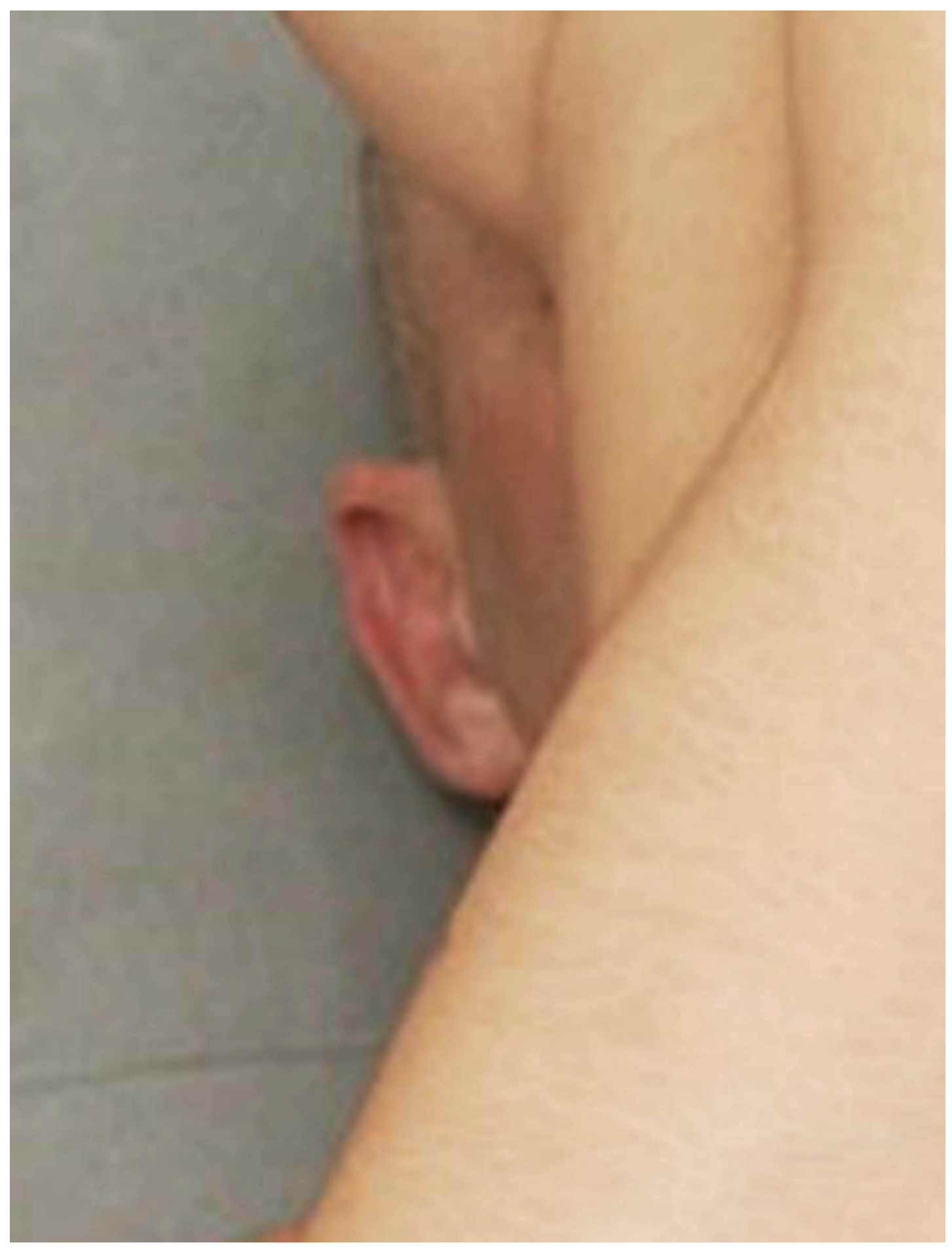




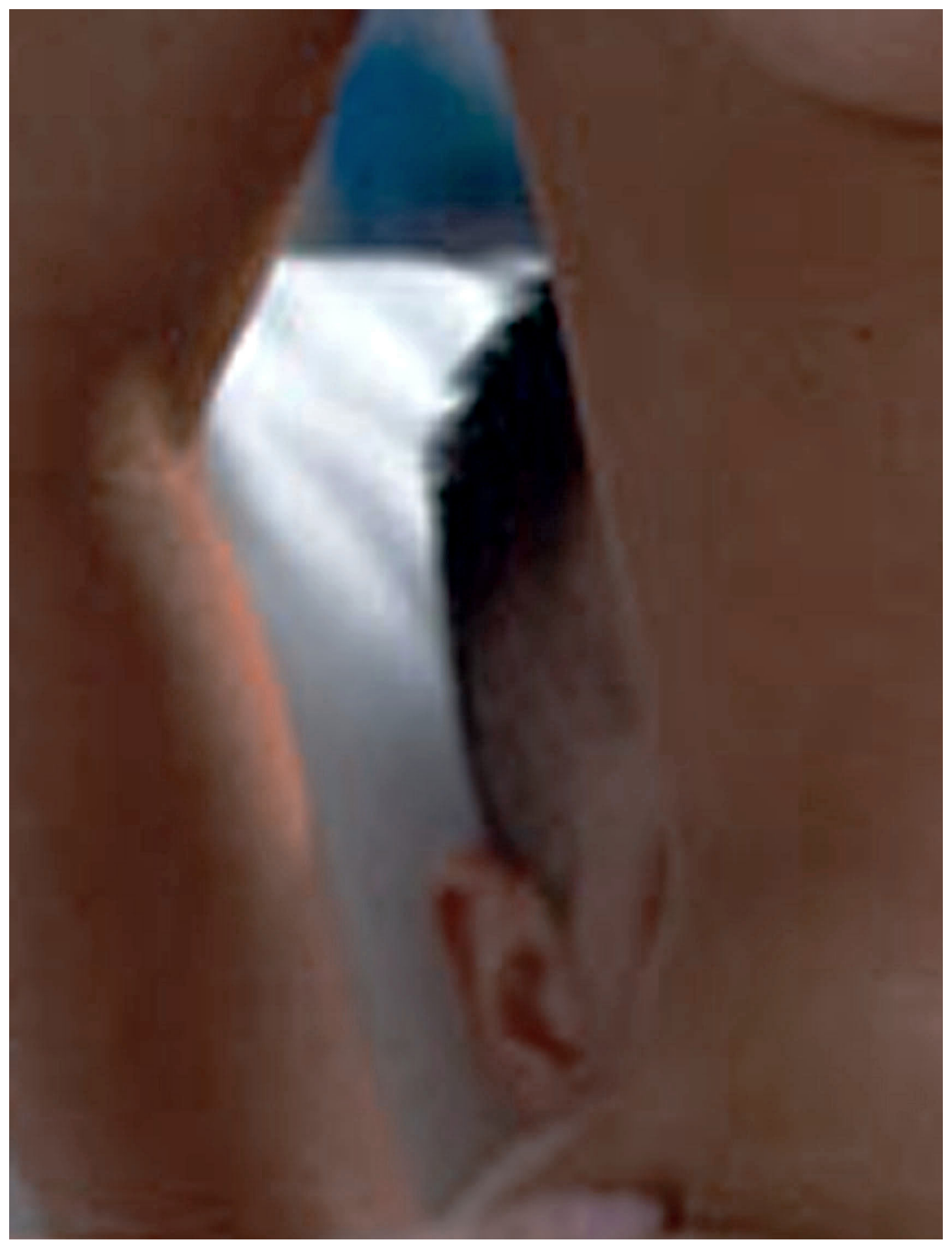




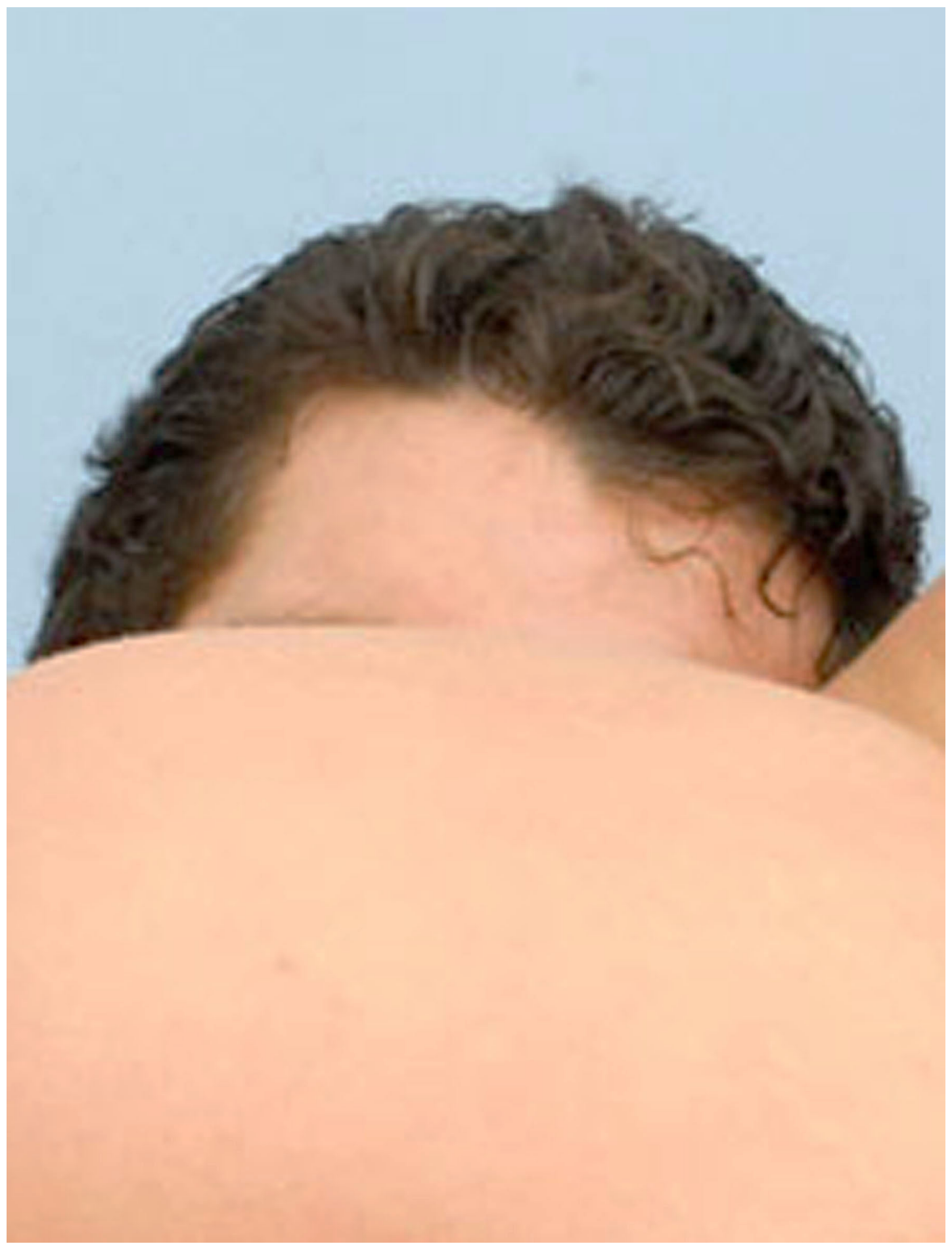




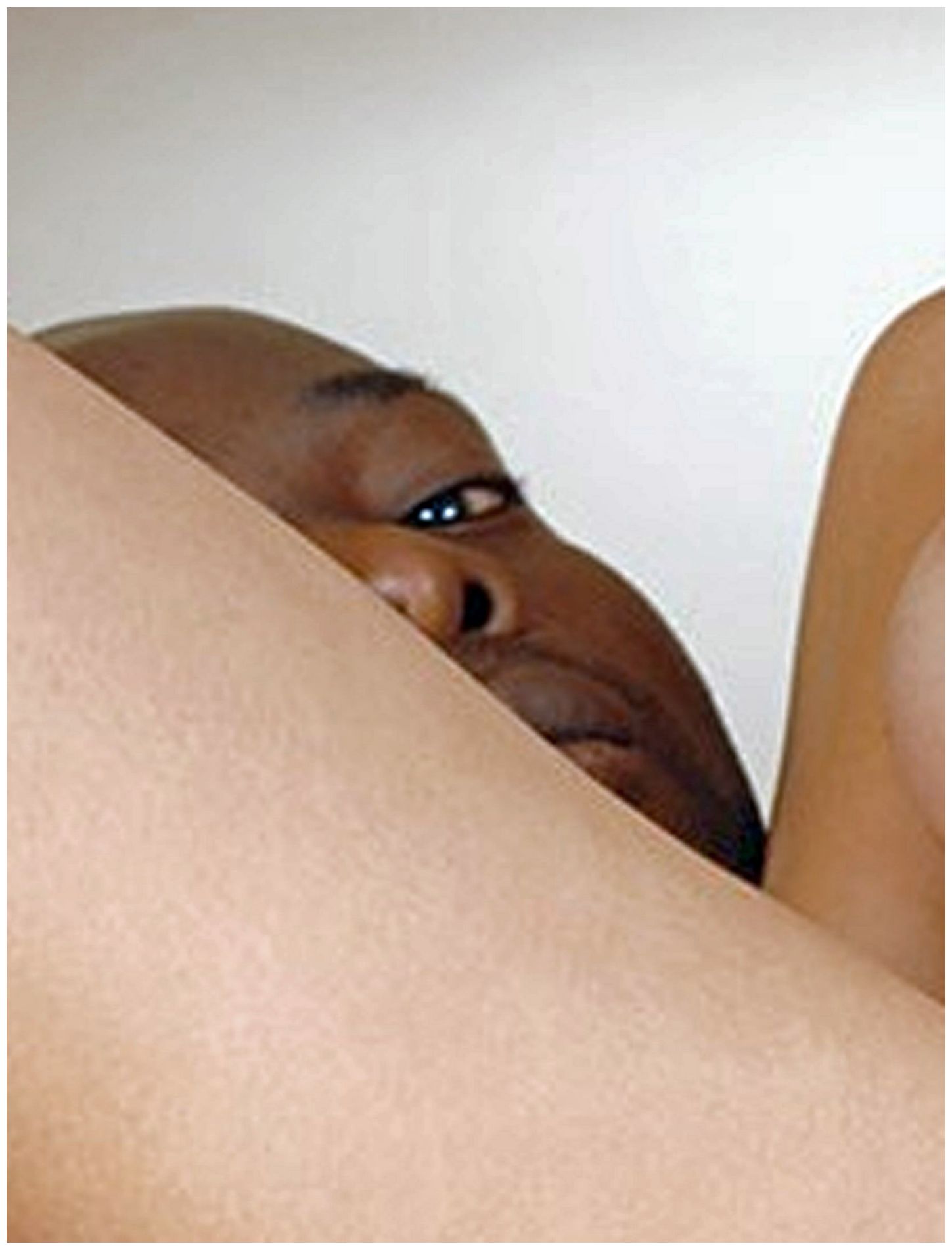




\section{Mario Ramiro}

Sujeito Oculto 